\title{
Perspectives of developing nursing education in Nepal
}

\begin{abstract}
Although nursing is well thought-out as valued and a public service leaning profession but the quality of nursing education and future of nurses remains a growing concern with International standards in Nepal. The perspective of nursing educationists reveals the scholastic, academic and practiced loom to understanding advancement in this sector. Nepal has been escalating its branches of nursing education in the Government as well as in private sectors throughout the country since 1990s. But, the development seems not to be so fruitful. The regulatory bodies and legal provisions are not so passionate towards the quality education and commercialization of nursing sector has increased drastically with numerous private nursing colleges which generate increased quantity of nursing professionals with a reduction of prospects for career and employment. The monopolies of private investors in nursing education are everincreasing day by day. The majority competent nurses desire to service in developed countries, such as the UK, North America, Australia and New Zealand due to the ineffective management strategy to hold nursing personnel in Nepal with worldwide standards. The nurse-population ratio low down in similarity to worldwide standards which definitely influences the quality of care in Nepal. There is lack in monitoring and government regulation of international nursing standards in quality education, production of effective nurses and frequently observed social and professional exploitation of nurses in Nepal. Also, nursing guidelines and policy making are not sufficient to flourish this profession. Therefore, the aim of this review is to explore the developing nursing education and examines diverse factors affecting the quality nursing education highlighting different challenges towards nursing profession and nurses in Nepal.
\end{abstract}

Keywords: exploitation, leadership, migration, nursing, privatization, professionalism
Volume 5 Issue 4 - 2018

\author{
Satyam Prakash,' Prativa Yadav, ${ }^{2}$ Khushbu \\ Yadav $^{3}$ \\ 'Department of Biochemistry, Janaki Medical College Teaching \\ Hospital, Janakpurdham, Nepal \\ ${ }^{2}$ Department of Nursing, Krishna Medical Technical Research \\ Center, Janakpurdham, Nepal \\ ${ }^{3}$ Department of Oral Pathology and Microbiology, Nepal Dental \\ Hospital and Technical Research Institute, Janakpurdham, Nepal
}

Correspondence: Satyam Prakash, Assistant Professor, Department of Biochemistry, Janaki Medical College Teaching Hospital,Tribhuvan University, Nepal,Tel +977 984I603704, Email sprakashy2424@gmail.com

Received: December 29, 2017 | Published: July 17, 2018

\section{Introduction}

Since the 1990s, nursing has turned into a progressively more eye-catching occupation for women in Nepal. ${ }^{1,2}$ With the innovative millennium, nursing sector has advanced gradually and enrolment in nursing education is enhancing and charming at this moment in Nepal. Nursing is a practice discipline, and being a "doing profession" is vital to encompass speculative fundamental knowledge for their performance in their daily activities in order to accomplish their liability completely. Florence Nightingale, the founder of modern nursing, says "Nursing is the care which puts a person in the best possible condition for nature to restore or preserve health, to prevent or to care disease or injury focusing the environmental theory". ${ }^{3}$ Nurse is solitary the one who lifted nursing to the stature of a reputable line of work for women. A competent nurse is known by her knowledge, training and skills make a competent nurse while complete nurse is known by positive attitude. The prime goal of nursing education is to convey nursing knowledge and to assist learners to attain the essential expertise and approach allied with nursing practice. ${ }^{4}$ Professionally, nursing education include the three realms of learning which are cognitive, affective, and psychomotor domains. ${ }^{3}$

Nepal with the advancement of growing nursing education and its rapid privatization has led to unforeseen consequences. There is a range of problems in nursing education that are faced with improper quality education, joblessness and uncertainty, pressure of heavy workloads, lack of skilled manpower, globalization, privatization, small pay, mistreatment in job setting, lack of striking strategies, lack of supervision and control, unsatisfactory in-service education, migration of nurses and brain drain. Nursing education in Nepal has not sufficient manpower for technical instruction in government as well as in private sectors. Although the production of nursing professionals is in increasing order but due to lack of government policy nursing education are profession are facing lots of obstacles all over the country. Therefore, the objective of this review is to briefly highlight the challenges and consequences in nursing quality education and quality nursing service in Nepal.

\section{Past and present of nursing education}

Before 1950, Nepal was inaccessible to coincide with developed countries in health sector. ${ }^{5,6}$ There was neither a university nor appropriate medical and health education about fifty years ago., ${ }^{1,7}$ There were thumbs down public health programs, few hospitals, no laboratories, no paramedics and only less number of Nepalese doctors and unsupplied with Nepalese nurses. ${ }^{1,8}$ But, gradually with strong and determined efforts of past years, noteworthy achievements have been made in the health sector. Ever since the inauguration of nursing education in 1956, there was constantly scarcity of nurses in Nepal due to ineffective education guiding principle. With historical growth of nursing sector it has crossed three junctures: formative period, transformative period and globalised period. Nursing education started under the Ministry of Health $(\mathrm{MoH})$ at Surendra Bhawan (Sanepa) in 1956 and the development in requisites of education and 
development lingered relatively slow. ${ }^{7,-12}$ Being started from a single school and moved to Institute of Medicine (IOM), Maharajgunj in quick succession with growing evidences of nursing education now.

Today, nursing education has escalated its branches and networking with university campuses along with numerous affiliated colleges under Tribhuvan University (TU), Kathmandu University (KU) and Pokhara University (PU), Purbanchal University (PU), Council of Technical Education and Vocational Training (CTEVT) and also an sovereign body B.P. Koirala Institute of Health Sciences (BPKIHS) at both government and private sectors in different regions of Nepal.

Gradually, various nursing colleges \& ANM centers were recognized \& advanced in different time periods. The specialized post graduate programme in "Master in women Health and Women Development" was launched in 1995. In 1996 (2053) Basic B. Sc Nursing a four year program was introduced in BPKIHS, Dharan and the institute of medicine also started four years B. Sc Nursing in 2005 (2062). Currently, there are numerous new campuses for PCL as well as Bachelor programs of Nursing under affiliation of T.U, K.U., P.U., \& C.T.E.V.T since 2005. Only ten percent male students were registered in nursing programs in 1986 \& clogged in 1990. On the whole, four batches of male students graduated in PCL nursing campuses and more often they had completed master level. ${ }^{13,14}$ But, once again male students have been given $15 \%$ reservation in nursing education currently in 2018 by government of Nepal to reduce the gender discrimination. Nursing education experienced quantitative and qualitative changes steadily and took approximately further two decades to progress into specialization in post graduate nursing., ${ }^{73}$ Nursing education focused with changes as center of attention at the certificate level to highlight prospective functions in the public health and at the bachelor level to focus on advancement of leadership skills. Six levels of nurse education from ANM to Ph.D. in Nursing were accessible in Nepal by the academic year of 2012-13 which are as follows. ${ }^{15}$

\section{The auxiliary nurse midwifery (ANM)}

The courses for ANM training started in the late 1960s with goal of organizing a nursing workforce to work in rural health posts providing Maternal and Child Health Services in Nepal. Near the beginning 1980s, only just five ANM programs were under Tribhuvan University. Gradually, the number increased to 50 after taken over by CTEVT in early 1990s which all runs privately nowadays. Many qualified ANMs remained jobless and over half of the 50 programs are in capital of Nepal, Kathmandu. ${ }^{15}$

\section{The proficiency certificate level in nursing (PCL) or staff nurse}

Before the establishment of CTEVT in 1989, six staff nurse campuses were in Nepal under the purview of the state which qualified totality of just over 250 nurses annually. The number started to increase in the 1990's with thought of training more staff nurses for the district centre hospitals and other government hospitals all through the nation. Even though accurate statistics are not accessible, but about 110 programme, each training between 35 and 60 staff nurses a year and 101 were registered under the CTEVT as NNC record suggested in early 2011. Several of the new programs are run privately, under the purview of the CTEVT. Each year unregistered training colleges opened and a small number have been stopped up through the preliminary study period..$^{15}$

\section{Bachelor of science in nursing (B.Sc. Nursing)}

With the development in health sector in 2013, altogether 40 programs were acknowledged with University to run for B.Sc Nursing programme: 8 in the Tribhuvan University, Institute of medicine; 21 with Purbanchal University, 8 with Kathmandu University, one with BPKIHS, Dharan and additionally 2 with Pokhara University respectively. ${ }^{15} \mathrm{~A}$ lot of nursing colleges opened in past few years and B.sc nursing is alluring nowadays in Nepal.

\section{Post basic bachelor in nursing (PBBN)}

After the completion of 3 years PCL nursing and 2-years postregistration clinical experience, the students are enrolled for this bachelor level programme in nursing. In 1996, Tribhuvan University started this programme and presently affiliated: eleven under IOM, TU; 23 with Purbanchal University; 4 with Kathmandu University; 1 with BPKIHS and one in the Bir Hospital nursing campus in Kathmandu. ${ }^{15}$

\section{Masters in nursing (MN)}

Currently, five M.N. programs are available in Nepal: four are under the TU, IOM, one in BPKIHS since $2013 . .^{15}$ these programme opportunities are imminent for those who are focused on academic activities.

\section{Ph.D. in nursing}

Maharajgunj Nursing Campus in Kathmandu started this programme in 2011 with two candidates per year by TU, IOM. ${ }^{15}$

\section{Privatization of nursing education}

Privatization is a work of plummeting the function of government or increasing the responsibility of the private organizations of society in gratifying people's desires and fulfilling the needs. Simply, it means to decrease the over burden of government relying more on the private sector. ${ }^{16}$ Recently, there has been a massive increase in the privatization of nursing education with rapid expansion in the number of nursing colleges in Nepal. No doubt, expansion of nursing education by private sector reached its remarkable achievements, but is full of multiple challenges. One of the tough challenges is to provide quality of education with optimum standards set by Nepal Nursing Council (NNC) and universities. With the increasing number of nursing colleges in the country, some of private nursing colleges are good and rest others are not up to the nursing standards. Nowadays, nursing sector is thought to be an attractive area for private investors.

The lucrative opportunity for the private sector to invest in health education, occurred in early 1990s broke the government's monopoly in delivering health related education including nursing education and created the private sector as champion in the health sector. ${ }^{17}$ While this development, advancement and rapid privatization led unforeseen consequences frequently and transformed service business into commercial business as huge monetary game. There is unhealthy competition among private business people and investors. It is a bitter fact that non-technical runs the technical colleges, hospitals, laboratories and other type of health programs who do not have adequate expertise to run these programs. Consequently, nursing science has also turned into commercial business in Nepal due to lack of stringent legislation and loopholes in governing policy. Every private investor is involved only to earn and spin money which made nursing education as a pure profitable business rather than curative public health service. 
Despite the advancement, quality of today's nursing education seems "not ideal and not very good" while considering effective quality education and production of excellent nurses for affordable healthcare. In Nepal, specialized post graduates in nursing subjects and also bachelor graduates in nursing are involved in teachinglearning activities at different nursing colleges of Nepal. Besides that, doctors, specialized post graduates in Anatomy, Physiology, Biochemistry, Pharmacology, and Microbiology along with Master's in Public Health are also involved in teaching for basic science subjects. It is often pragmatic that due to lack of sufficient faculty members in this field, newly fresh bachelor nursing graduates are also projected in teaching activities for bachelor level students. But, with the situation it's reasonably questionable that the nursing education quality promotes or not? Unnoticed truth is also observable at bachelor level courses, most of nursing colleges hire newly fresh bachelor nursing graduates to minimize the costs on teaching faculties in spite of maintaining the quality standard of education. Specialized post-graduates are sparsely available at peripheries and if available, nursing colleges are not supposed to recruit them. Rather, they are offered either as standing faculties or part timers to reduce the expenses. Regular full timer faculties are typically not observed in private nursing colleges as per the criteria of Universities.

The faculties members involved in teaching at private nursing colleges from nursing science, basic and clinical Science, either the part timer or full timer experiences that there is no system of payment and are never paid salary on due time on monthly basis or as mentioned in agreement. Professionals associated in private nursing college experiences that private management habitually bother the teaching faculties when they address for their payment on time and adequate salaries, remuneration and incentives. The monopolies of private investors are increasing gradually more and more. Similar conditions are common with the nurses working at different private hospitals in Nepal. They often feel unsafe from job and social security as well as exploited in several ways. During inspection of NNC and Universities, nursing colleges utilize scanned certificates, show fake faculties standing, manages documents and often tries to bribe the inspection team. The different unhealthy possible techniques are applied by private investors to manage and please the inspection team to encircle and round up their hidden but frequent drawbacks in colleges. This also parallels in private hospitals frequently. The day to day activities and actions of nursing colleges in regard to quality education and quality production of nurses are often problematic with different aspects. Insufficiency is in terms of infrastructure and clinical material to teach the nursing diploma, bachelor graduates and postgraduates, deficient professional knowledge and poor competencies definitely affects the quality of care and knowledge of nursing professionals. Another emerging challenge is newly establishing nursing college in terms of infrastructure, clinical material, trained and regular faculty, and admission process. Factors like inadequate training, technical skill of the health force, improper deployment, inefficient skill mix, poor working environment, and lack of opportunities for personnel management are few reasons affecting quality in nursing education. The teaching and technical skills of nursing education also vary from one to other private Institutions. National guidelines are not available and improper for teaching, and as a result, they are not exposed to recent changes in the program and policies. But, the excellence and reliability of nursing education should be maintained with the standard curriculum and teaching learning practices to assemble nationwide necessities and to compete in the international marketplace of nursing. The risk of nursing education sector is becoming an object of commercialization which should be prevented as well.

Nursing education, its quality and production of effective nurse is a critical issue for National health care system. One of the most prominent challenges is the average cost of education in a private versus government nursing college. There is also a huge disparity in costs and fees of government and private nursing colleges. So, nursing education in a private institute is very expensive affair and captures only that segment of the youth and parents of high financial status who can afford it. This enormous profit motive on the part of private management can ruin quality of nursing education in Nepal and Nepalese health system in long run. So, it is of an urgent need for regulating bodies to scrutinize and ensure uniformity in admission, fees, curriculum, and accreditation for degrees in nursing.

The growth of nursing colleges is due to the large-scale privatization of nursing education and lack of government control over this issue. One side of the coin shows that nursing colleges are budding quickly, but the other side highlights acute shortage of faculties, low quality education, insufficient infrastructures and physical facilities which makes the environment irony to grow. Undoubtedly, nursing education in Nepal has expanded in past few years, but it continues to remain inadequate with the needs of the country in health sector. At this juncture, it should be monitored with stringent implementation of the rules set by Nepal Nursing Council and Universities so that nursing education could not be compromised in the long run in search of appropriate nursing health work force with adequate skill mix for quality service.

\section{Quality education and quality service}

Due to concerted efforts consistently in past years, significant achievements have been made in the nursing sector. But, the overall quality and integrity of nursing education has declined recently, especially after the entry of the private sector in the nursing education business. ${ }^{17}$ The theoretical aspects in colleges as well as practical aspects in hospitals are important for nurses to venture quality service. But, the nursing students are always in trouble due to high benefit strategy of private sector. Students habitually practice that the curriculum designed by university for a year are completed on the package basis salary given to teachers within short duration of time. Colleges often do not hire adequate number of specialized nursing professionals as per the requirement and also no laboratories works are performed properly. The Training Institute for Technical Instruction (TITI), CTEVT, and Nepal carries Training of trainers (TOT) for the faculties teaching in technical education. But, colleges do not prefer to send their faculties to to any such type of skill developing training to reduce the extra expense.

Practical activities and teaching-learning activities are not optimum in private colleges but always emphasizes about quality education, hospital exposures and clinical skill developments as their commitment during admission at the beginning of session. But, implementation has not been creative. Newly fresh graduates in nursing professionals, less experienced teachers are mostly promoted by private colleges on low salaries to condense the operating expense. Other than the college fees and university charges, several other supplementary charges are also taken in the mid of session with additional saddle monetary burden to parents and students on the name of developmental fees. Students 
are of in tribulations on-the-job practical in districts go for practicum in district level hospitals where there are not adequate patients for all students to serve. ${ }^{17}$

Another important aspect is modification of the examination pattern conducted by the universities. The examination of universities does not commence routinely per year and students often suffer from delayed session. The question papers in entrance examinations are also not up to standards for bachelor graduates. The reason may be that the growing nursing college's seats should be fulfilled and finally the result perils the standards of nursing education. Afterward, student's standards are also not maintained and optimistic for nursing science. Subsequently, University examination centers are managed by the private investors during university examination to make the best result on screen of viewers to grab the students for new session accordingly. Major lacking resembles in question pattern of different subjects as they are not focused on curriculum whole heartedly rather focused on good results to nurture and fulfill the number of seats of private colleges. Besides that, good results also counts for the reputation of universities. The internal assessments and practical assessments are also not properly scrutinized in private nursing colleges by universities due to surplus load of affiliated colleges. The proper assessment on question pattern, examination system and hospital practical is quite essential to enhance nursing education.

Private nursing colleges benefit from the ambiguity of regulatory bodies as transparency regarding quality education and health service has never been consistent so far in Nepal. Some universities follow the faculty post approval system but some universities have no any criteria developed yet for the post approval of faculties working in private nursing colleges. Regular visits by NNC and universities are important time to time rather than once a year. An analysis of physical infrastructure, quality of hospitals where nurses will do practicum and human resources should be taken into considerations before providing license to private institute to offer nursing education. The rules and regulations are only on bridges of paper, but execution is not proper. $\mathrm{NNC}$ and Universities should be proper, enthusiastic and strict with its guideline to maintain the quality and integrity of nursing science.

\section{More production and less utilization}

With the charm of nursing science, every year the production of PCL, bachelor and post graduate nurses are at large numbers is noticeable in Nepal. In addition, students studying nursing in India and other countries are also enormously produced and getting back to Nepal. Currently, nursing education is paying attention to coincide worldwide training standards and setting up nurses for the international market. ${ }^{15}$ The trained nurses and their production are increasing in Nepal more than the capacity to occupy them. At this stage, it's optimistically important but an unanswered question that how Ministry of health and National health care system will give them job placements in nursing colleges and hospitals of Nepal. Net demand and net supply ratio of nurses in the country is very crucial to know with rapid production of nurses, as government and regulatory bodies are in failure situation to absorb all graduates and PCL nurses. ${ }^{17}$

According to Nursing Council of Nepal (NNC), by the end of September 2016 there are 38, 759 Staff nurses, 26518 ANMs, 818 foreign nurses (total) are registered. HMIS reports that Nepal have 0.68 doctors and nurses per 1,000/population as of selected staff Significantly less than the WHO recommendation of 2.3 doctors, nurses and midwives per 1,000/population. There is a challenge in the employment of these nurses in the country. The initial remarks of a study in early 2013 carried out by the CTEVT, Nepal recommended that various new nurse graduates had acknowledged themselves with not paid voluntary work in healthcare institutions in Kathmandu and remained voluntary for between 6 and 9 months after graduation. ${ }^{18}$ Even though there is saturation level of newly qualified nurses in hospitals in Kathmandu, the staffing condition outside the valley is detrimental. Furthermore, the turnover of junior nursing staff vestiges high in major municipal hospitals but is in scanty situation in rural areas. The majority of competent and experienced nurses desire to employ in developed countries, such as the UK, North America, Australia and New Zealand. ${ }^{15-19}$ There is no efficient managing policy to maintain a nursing workforce, predominantly in rural Nepal. Nursing education, after all, should not be a business profitable to few private sector people and a net loss to the nation, students and their parents. ${ }^{17}$ Government has not been able to command, control and standardize the private nursing education marketplace. The government is investing a huge amount of budget to produce nurses who may not get employment at the end of the day. The requirement of domestic nursing workforce has been ignored in Nepal which demands vital interest of policy awareness.

\section{Frustration, stress and exploitation}

It is obvious that many Nepalese girls are attracted towards the nursing profession but, is an extremely stressful job. Nursing is distinguished by experience to a large array of potentially hectic state of affairs and circumstances. ${ }^{20-23} \mathrm{Job}$ stressors comprise issues such as unnecessary or soaring workloads, ${ }^{24}$ crooked and unsocial hours of employment ${ }^{25}$ body fatigue, ${ }^{26}$ the poignant anxiety of dealing with ill patients and their relatives and with patients whose behaviors are barbed, ${ }^{27}$ poor employees prop up, ambiguity regarding cure, argument with other nurses, administrator and medical staff, dealing with decease and dying, supervision obscurity, problems relating patient trouble, apprehension about methodological acquaintance and skills. ${ }^{28,29}$ The nurses with higher works loads and burdensome responsibilities with insufficient and inefficient nursing staff endure diverse pessimistic and unconstructive higher levels of depression.

Nursing students are more vulnerable to higher levels of stress owed to the intermediary environment of college life which impinges on students' healthiness, fitness and scholastic effectiveness. ${ }^{30-33}$ Researchers have acknowledged that apparent stress levels are skyscraping among nursing students. ${ }^{31,32}$ Principally, the stress among the student nurses can be divided into four categories, the social stress, financial stress, academic stress and clinical area stress. Academic and clinical stress is common among nursing students whereas social and financial stress are more common in job holders. Less exposure and lack of experience, terror of making faults, complicated patients, embarrassment at being under judged by faculty members, tormenting about giving patients the erroneous information or medicines and worry about probably harming a patient are just a few of the stressors for student nurse..$^{34}$ The stress among nurses due to job unhappiness, deprived presentation and performance, worker abandonment, career turnover, inferior profession concern are more common in Nepal. Many nursing staff complains that hospital management does not even snoop to their concerns. ${ }^{17}$

The professional career for newly graduated nurses is extremely challenging and hard in Nepal. Due to lack of experience, newly 
graduated nurses are in difficulties to search out job in colleges and hospitals in the market. So, a large number of fresh nursing graduates are either idle or undertake unpaid or partially paid volunteer jobs. Some nurses who were working as a volunteer were forced to work for long hours. Others suffered from humiliation and discrimination in the work place ${ }^{17}$ there is an urgent requirement to formulate nationalized payment system and employment configuration in both the government and the non-government sector within the healthcare sector in Nepal. The exploitation of nurses in working institutions and colleges are regularly exposed by electronic and printed media. There is far difference in payment in government sector, private and INGO sectors which is an essential need to be balanced instantly. In contrast, newly graduate nurses deserve to be appreciated and not demoralized in a competitive struggle market. The regulatory body, Nepal Nursing Council should take inventiveness for the Nursing workforce management in Nepal. ${ }^{15}$

\section{Migration of nurses}

Every year 250,000 adolescence are accounted to run off from Nepal for advanced livelihood, service, enhanced earnings, proper education system, attracting western standard of living, steadiness and safekeeping as it appears incapable for youths in this country. ${ }^{35}$ The migration of nurses is not new in Nepal due to high unemployment and unsecured future in their home country. The systemic data is not so much ubiquitous to be familiar with the extent of migration of nurses from Nepal to developed countries and the persuading features of their move from country. But, better working condition and environment, educational opportunities, better remuneration, good educational system, occupation contentment, better professional career, the excellence of organization and authority, political stalemate and conflicts, confrontation, and the menace of violent behavior in the workplace and students can do job, earn and study alongside could be the possible encouraging factors for Nepalese Nurses to wander in a foreign country. ${ }^{36}$ The data depicts 4155 nurses migrated abroad till 2013. ${ }^{15,18,19}$ The USA, the UK, Australia and Canada are top four countries that receive trained nurses from Nepal. ${ }^{37,40}$ As a result, Nepal is losing skillful manpower of the country with serious scarcity of trained, experienced and skillful manpower which outspokenly goes in front to financially viable failure of the country. ${ }^{15,17} \mathrm{Nepal}$ requires a long term health policy that takes into account of actual demand of nurses in the country and well designed policy that offers attractive incentives, lucrative career path and better social security. Unless these conditions are achieved, the country might be losing its young and dynamic nurses.

\section{Need of professionalism among nurses}

Professional nursing practice is a devotion to empathy, compassionate and well-built moral ideals; consistent progression of identity of self and others; responsibility and accountability for perceptive performance; indicative of strength of teamwork and limberness. Professionalism means that all nurses care for everyone similarly, and do their finest to guarantee that the utmost quality care is being given. This consists of a commitment to ideology of impartiality, truthfulness, reverence and reliability. ${ }^{41-44}$

Nursing professionalism stems from nurses developing their practice. ${ }^{42}$ there are plenty of expectations with Nepalese nurses who hunt for professional practice have to bestow the finest promising quality care to all patients, despite of the circumstances or who they are. A nurse also needs to continually improve. But, the situation seems somewhat sparse in Nepal. Despite the fact that all nurses have a responsibility to cooperate in building professionalism, there are several barriers that dump in the way. One of the most important barriers is a disparity in educational background among nurses. The dissimilarity in different levels of education among different nurses can dole out to divide, but nurses ought to work to diminish the effects of educational inequality among them. Further, the responsibility clash due to numerous tasks, discrimination in provision of nursing services, lack of inspiration and challenges, conflict in transformation, unfairness in remuneration/settlement and other conveniences, and management/ailment focused nursing practice are with lots of barriers towards professionalism.

Moreover, gender issues acts as a barricade to professionalism. Earlier, men were also involved in nursing in Nepal but gradually, female dominance occurred in this profession. Nowadays, it's fully female-dominated and women oriented profession. But, egalitarianism and social security among the sexes in the profession will serve to enhance professionalism in nursing field. Once again, issues has raised optimally in Nepal for men to enter nursing profession and looking ahead for the decision of governing regulatory bodies in coming future with positive outcomes. Currently, $15 \%$ reservation has been announced by Government of Nepal to male students in nursing which can be a welcome decision of the government to solubilize the gender disparity. The other probable reasons frequently observed are due to the lack of in this profession hospital administration, insufficient clinical skills, ignorance, low pay salary, poor working condition, lack of competency, short of team management and personal disputes as the risk factors for unprofessionalism among them. Nurses should also make certainty that they have the good preparation and exercise, knowledge, experience and dexterity considered necessary to execute the responsibilities that they are anticipated to complete for reputation of their profession and professionalism.

\section{Need of transformational leadership}

Leadership grasps the input to renovate the nursing society. As public principles revolutionized to draw attention more on human being requirements for trust, dedication, empathy, conscientiousness, reverence, dignity, opportunity and innovative approaches of nursing leadership goes forward. ${ }^{45}$ Transformational leadership is a novel leadership paradigm that includes the sensitive and poignant character of people by placing importance on interpersonal relations. Transformational nursing leaders have countless reciprocally strengthening leadership personas that let them to bloom in surroundings that cultivate system, transformation, opinionated consciousness, and relationship. ${ }^{46-48}$

Women campaigner and women confederacy can play a chief role collectively with media and public motivation. The issue of Leadership is in sticky situation among nursing professionals. Faithful goals of nursing should be the common language of nurses on policy formulation. The most important point of view is that the nursing education cannot go the right way if not convoyed in analogous with the other applied and health sciences to bridge the gap and balance the discriminations and disparities within nursing profession. Although, nursing leaders contributed to the incredible advances in nursing but challenges are with nurturing aspect of nursing care and quality nursing education. The leadership of Nepal Nursing Association and Nepal Nursing Council can play main role in pressurizing policy makers and planners in intensification superiority of treatment, 
care, and services in the civic hospitals successfully and proficiently mobilizing the inadequate existing assets and escalation of nursing profession. But, their attitudes have not been optimistic, enthusiastic, inventive and not changed so far. There is an urgent need on leadership capacities development program, establishing collaboration and synchronization, strategy of action, established precedence, structure strategies, recognizing objectives rather than only being a garrulous on public speeches to enhance quality education, effective nurses, good quality service and rights of nurses. A transformational leadership can renovate this profession to new growth and vision of nursing education.

\section{Conclusion}

Undoubtedly, nursing in Nepal bannered promptly towards mounting it as peculiar profession. Better career options, secured identity, specialization and service towards nation in delivering curative and promotive health service with higher education is an inspirational panorama for females nursing as a career. The lack of independence, ineffective organizational support, guiding principles and biased decisions, defective monitoring and assessment system, insufficient resources, lack of promotion, social stigma, and ineffective cooperative negotiations, narrow research studies and its relevance are the hindering factors in nursing education. Major limitation stumbles in nursing education are upon scarcity of qualified teachers, rapid privatization, supervisors to administer the student's clinical practicum, lack of working environment, restricted prospect of career development and job opportunity, restricted prospect for nurses to get experience to recent exposures, lack of appropriately designed in-service education programs, scarcity of nursing and midwifery workforce, and incapability to keep hold of qualified nurses in the remote areas and migration of skilled nurses from Nepal.

The positive outcomes in the development of nursing education is on frontline but still, it needs to be addressed with strong policy and legislature for quality education of nursing in Nepal. The level of nursing education could be enhanced by increasing faculty members, regular evaluation and scrutiny of nursing curriculum development, balancing the migration of nurses and more confidently strict control over the escalating privatization of nursing sector Licensing, registration and other Standard-setting measures facilitate governments to guarantee eminence of care. Policies should be invented and must be put into practice in order to authorize nurses and make them secure accordingly. The political hindrance in the service sector should be depressed and evaded. Furthermore, harmonization between the concerned organizations with rules and regulations for job security and uniformity should be implemented and seriously maintained.

\section{Future recommendations}

Nursing needs to achieve autonomy in controlling and maintaining the integrity of its professional education and united membership has to be recognized. Nursing is primarily composed of women, who have been and continue to be dominated by the physicians and hospital administrators in many health care institutes that should not be overlooked. Privatization of nursing education should be in control of government. Trained and efficient manpower should be involved in rapid way. New nurses have to understand how nursing trends and issues synthesize the technical, ethical and organizational issues in the ever evolving health care arena of nursing.

\section{Acknowledgments}

None.

\section{Conflict of interest}

The author declares that there is no conflict of interest.

\section{References}

1. Institute of Medicine. Health learning materials project: Post basic bachelor of nursing curriculum. Kathmandu, 1989.

2. History of Nursing in Nepal. 2017.

3. Verghese A, Shrestha NM, Singh S. Fundamental of Nursing. $2^{\text {nd }}$ ed. Kathmandu: Health Learning Material Centre; 2004.

4. Florence Nightingale (1820-1910).

5. Institute of Medicine. Annual Report: Department of information technology, Kathmandu. 2011.

6. Institute of Medicine. Certificate nursing curriculum handbook. 4th ed. Kathmandu: Health Learning Materials Centre; 1997.

7. Thakur LS. Fifty years of nursing education. Kantipur News. 2006.

8. Institute of Medicine. Health learning materials project: Post basic bachelor of nursing curriculum. 2002.

9. Ministry of Health and Population of Nepal. Fact Sheets: Health Facilities \& Health Human Resource under Ministry of Health and Population (MoHP). 2011.

10. Karki DB, Dixit H. An overview of undergraduate and postgraduate medical education in Nepal and elsewhere. Kathmandu Univ Med J. 2004;2(1):69-74.

11. Sigdel R. Nursing Education in Nepal: Historical Perspective. Health Prospect. 2011;10:9-10.

12. Streefland P. The frontier of modern western medicine in Nepal. Soc Sci Med. 1985;20(11):1151-1159.

13. Dixit H. Nepal's quest for health (The health services of Nepal) Kathmandu: Educational Publishing House; 2005.

14. Shakya ND. Nursing Practice Theory and Quality of Nursing. Journal of Nursing Education of Nepal. 2000;2(1):1-6.

15. Adhikari R. Vacant hospitals and under-employed nurses: a qualitative study of the nursing workforce management situation in Nepal. Health Policy and Planning. 2015;30(3):289-297.

16. Savas ES. Privatization and Public-Private Partnerships. New York Chatham House Publishers; 2000.

17. Rai DS. Growth of nursing education sector and its effects on professionalization of nurses in Nepal. IOSR Journal of Nursing and Health Science. 2014;3(4):34-39.

18. Adhikari R. The business nursing complex: understanding nursing training in Nepal. Studies in Nepali History and Society. 2008;13:297-324.

19. Adhikari R, Grigulis A. Through the back door: nurse migration to the UK from Malawi and Nepal, a policy critique. Health Policy Plan. 2014;29(2):237-245.

20. Buchan J. Counting the Cost of Stress in Nursing. Nursing Standard. 1995;9(16):30-31.

21. Collins VA. A Meta-analysis of Burnout and Occupational Stress. International: Section B: The Sciences \& Engineering. 2000;60(9B):4942. 
22. McAbee R. Occupational Stress and Burnout in the Nursing Profession. AAOHN J. 1991;39(12):568-575.

23. Santamaria N. The Difficult Patient Stress Scale: A New Instrument to Measure Interpersonal Stress in Nursing. Aust J Adv Nurs. 1996;13(2):2229.

24. Kelly JG, Cross DG. Stress, Coping Behaviors and Recommendations for Intensive Care and Medical Surgical Ward Registered Nurses. Research in Nursing and Health. 1985;8(4):321-328.

25. Kandolin I. Burnout of Female and Male Nurses in Shiftwork. Ergonomics. 1993;36(1-3):141-147.

26. Power KG, Sharp AW. A Comparison of Sources of Nursing Stress and Job Satisfaction among Mental Handicap and Hospice Nursing Staff. J Adv Nurs. 1988;13(6):726-732.

27. Podrasky DL, Sexton DL. Nurses' Reactions to Difficult Patients. Image: Journal of Nursing Scholarship. 1988;20(1):16-21.

28. Bailey JT. Stress and Stress Management: An Overview. Journal of Nursing Education. 1980;19:5-7.

29. Robinson JR, Clements K, Land C. Workplace Stress among Psychiatric Nurses. J Psychosoc Nurs Ment Health Serv. 2003;41(4):32-42.

30. Shiver CB, Scott-stiles A. Health habits of nursing verses non nursing students: A Longitudinal study. J Nurs Educ. 2003;39(7):308-314.

31. Burke K. Stress levels on diploma course affecting academic confidence. Nursing standard. 1999;13(50):5.

32. Mahat G. Stress and Coping: First year Nepalese Nursing Students in clinical setting. J Nurs Educ. 1996;35(4):163-169.

33. Singh C, Sharma S, Kumar R. Level of stress and coping strategies used by nursing interns. Sharma Nursing and Midwifery Research Journal.2011;7(4).

34. Sharif F, Masoumi S. A qualitative study of nursing student experiences of clinical practice. BMC Nurs. 2005;4(6):1-7.
35. Manandhar S. Who pays the price for Nepal's Brain Drain?. The Himalayan Times (Nepal). 2010

36. WHO. Migration of health workers, fact sheet. 2010.

37. Adhikari R. Perils and Prospects of International Nurse Migration from Nepal. Policy brief 2012. 2012

38. Adhikari R. The "dream-trap": brokering "study abroad" and nurse migration from Nepal to the UK. European Bulletin of Himalayan Research. 2010;35-36:122-38.

39. Adhikari R. From aspiration to dream-trap: nurse education in Nepal and Nepali nurse migration to the UK.

40. Baral R, Sapkota S. Factors influencing migration among Nepalese nurses. Journal of Chitwan Medical College. 2015;5(12):25-29.

41. Chitty KK. Professional nursing: concepts \& challenges. New York: Elsevier Health Sciences; 2005.

42. Clark L. Leading by Example. Nursing Management. 2008;15(6):12-17.

43. Girard F, Linton N, Besner J. Professional practice in Nursing: A Framework. Nursing Leadership. 2005;18(2):1-8.

44. Staples S. Are You a Nursing Professional?. Nurse Together.

45. Astin AW, Astin HS. Leadership reconsidered: engaging higher education in social change. Battle Creek (MI): WK Kellogg Foundation; 2000.

46. Davidhizar R. Leading with charisma. J Adv Nurs. 1993;18(4):675-679.

47. Trofino AJ. Transformational leadership: moving total quality management to world-class organizations. Int Nurs Rev. 2000;47(4):232-242.

48. Swanson JW. Zen leadership: balancing energy for mind, body, and spirit harmony. Nurs Admin Q. 2000;24(2):29-33. 